\title{
O GRITO DAS “CAMILAS" NÃO ECOA NA SOCIEDADE: A VISÃO DA EXPLORAÇÃO SEXUAL DE CRIANÇAS E ADOLESCENTES NA MÚSICA INTERPRETADA PELA BANDA "NENHUM DE NÓS"
}

\author{
EL GRITO DE "CAMILAS" ECOA NO EN LA SOCIEDAD: LA EXPLOTACIÓN \\ SEXUAL DE NIÑOS Y ADOLESCENTES EN LA VISIÓN INTERPRETADA POR \\ BANDA DE MÚSICA "NENHUM DE NÓS"
}

\author{
${ }^{1}$ Acácia Gardênia Santos Lelis \\ ${ }^{2}$ Mario Jorge Tenorio Fortes Junior
}

\section{RESUMO}

O presente artigo tem como objetivo analisar a exploração sexual de crianças e adolescentes, realidade presente na sociedade e identificada como uma das formas mais perversas de violação dos direitos humanos, evidenciada na letra da música "Camila" da banda Nenhum de Nós. A música "Camila" retrata a questão da exploração sexual de uma adolescente, que clama à sociedade a percepção da ausência de sua autonomia. Para esta pesquisa, o método de abordagem utilizado é o método dialético dentro de uma abordagem dedutiva, a partir da obra musical "Camila" interpretada pela banda Nenhum de Nós.

Palavras-chave: Exploração sexual, Direitos humanos, Desenvolvimento

\section{RESUMEN}

Este artículo tiene como objetivo analizar la explotación sexual de niños y adolescentes, la realidad presente en la sociedad e identificado como una de las formas más perversas de la violación de los derechos humanos, se evidencia en las letras "Camila" banda Ninguno de nosotros la música "Camila" retrata el tema de la explotación sexual de un adolescente que afirma la percepción social de la falta de autonomía. Para esta investigación, el método de enfoque utilizado es el método dialéctico en un enfoque deductivo, a partir de la obra musical "Camila", interpretada por la Banda Ninguno de nosotros.

Palabras-claves: La explotación sexual, Derechos humanos, Desarrollo

\footnotetext{
${ }^{1}$ Mestre em Direito pela Pontifícia Universidade Católica do Paraná - PUC, Paraná (Brasil). Professora de Direito Civil pela Faculdade Pio Décimo-AECPD, Sergipe (Brasil). E-mail: aglelis@infonet.com.br

${ }^{2}$ Doutorando em Direito Político e Econômico pela Universidade Presbiteriana Mackenzie - MACKENZIE, São Paulo (Brasil). Professor de Direção e administração pelo Centro Universitário Tiradentes - UNIT, Alagoas (Brasil). E-mail: $\underline{\text { mariofortes@gmail.com }}$
} 


\section{Introdução}

A exploração sexual de crianças e adolescentes configura-se numa das modalidades mais graves de violação dos Direitos Humanos, por isso está entre as maiores preocupações da sociedade atual, tendo em vista o alto índice de casos identificados por diversos órgãos nacionais e internacionais. O fenômeno é complexo, multidimensional, multifacetado e transnacional e tem suas determinações não somente na violência criminal, mas, sobretudo, nas relações macrossociais. (LEAL; LEAL, 2004, p. 268).

O tema em estudo foi incluído na agenda pública brasileira, em razão de denúncias realizadas por organizações estratégicas da sociedade civil, especializadas na defesa de temas relativos à mulher, às crianças, e aos adolescentes. A inclusão foi realizada pela Organização das Nações Unidas (ONU) e Organização dos Estados Americanos (OEA), em nível local e global, os quais, em defesa dos direitos humanos, se posicionaram especialmente contra a violência, o abuso e a exploração sexual comercial, o crime organizado, o tráfico de seres humanos e a escravidão. (LEAL; LEAL, 2002, p. 33). No Brasil, a exploração sexual infantojuvenil ganhou visibilidade na década de 1990, após a realização da Comissão Parlamentar de Inquérito (CPI) que investigou sua ocorrência em todo o país. A partir daí houve uma mudança de olhar sobre o problema, conforme a UNICEF,

\footnotetext{
Com o trabalho da Comissão Parlamentar de Inquérito (CPI) da prostituição infantojuvenil no Brasil, em 1993, houve um avanço na concepção dessa temática. A partir desse momento, a "prostituição infantil" passou a ser compreendida como Exploração Sexual Infanto-Juvenil, em sintonia com as diretrizes do Estatuto da Criança e do Adolescente (ECA), que diz, em seu artigo $5^{\circ}$, que "nenhuma criança ou adolescente será objeto de qualquer forma de negligência, discriminação, exploração, violência, crueldade ou opressão, punindo na forma da lei qualquer atentado, por ação ou omissão, aos seus direitos fundamentais". Nessa perspectiva, as organizações não- governamentais, o governo e as agências internacionais optaram pelo uso do termo "exploração e abuso sexual contra crianças e adolescentes", e não "prostituição infanto-juvenil". Isso porque se considera a prostituição um modo de vida que abrange determinado segmento social: ou seja, só o adulto pode optar por essa forma de garantir seu sustento. Uma criança, com menos de 12 anos, e um adolescente, com menos de 18, simplesmente não escolhem esse caminho, mas são induzidos pela prática delituosa do adulto.
}

A exploração sexual de crianças e adolescentes manifesta-se em decorrência de uma cultura de gênero e classe social, sobretudo na perspectiva de não se adotarem políticas públicas que incentivem a discussão no campo da educação sexual, nas escolas, nas famílias e na sociedade, em conformidade com o estabelecido nos artigos 86 e seguintes da Lei 8.069/1990 
que aprovou o Estatuto da Criança e do Adolescente (ECA). Assim, a exploração sexual mostrase como violência bimodal, pois atenta tanto contra os direitos da infância, bem como atenta contra os direitos da mulher.

A questão condicionante de se pensar a criança e adolescente como sujeito de direitos é ainda distante do que se apropriam os violadores e causadores da prática de exploração sexual, por estes entenderem que não existe a condição peculiar de pessoa em fase de desenvolvimento.

A diversificada fonte de pesquisa utilizada para aprofundamento do tema propiciou visualizar a necessidade de um olhar para a criança e o jovem como indivíduos, que necessitam de atenção, e, portanto, merecedores de proteção especial, bem como a questão de gênero que envolve a exploração sexual. Para a realização do presente estudo foi utilizado o método dialético, com uma abordagem qualitativa, através de pesquisa exploratória, que proporcionou aprofundamento do tema, sem, no entanto, pretender exaurir a discussão.

\section{A EXPLORAÇÃO SEXUAL DE CRIANCAS E ADOLESCENTES COMO MASSIVA VIOLAÇÃO DOS DIREITOS HUMANOS}

Apesar de a exploração sexual de crianças e adolescentes ser um tema discutido em todo o mundo, como uma das formas mais extremas de violação aos Direitos Humanos, constata-se, através dos resultados de pesquisas já realizadas, o alto índice de casos identificados nos municípios brasileiros. O enfretamento do problema pressupõe o conhecimento dos diversos fatores influenciadores para sua ocorrência, e, dentre eles, os fatores socioeconômicos e culturais são os de maior relevância.

Nesse contexto, constata-se que a violação aos direitos humanos de crianças e adolescentes ocorre também pela mediação financeira, e essa condição possibilita o poder para realizar qualquer tipo de violência, como a que caracteriza a exploração sexual de meninos e meninas a qual apresenta elementos de submissão e dominação, e reconfigura as relações de desigualdades sociais de caráter sexista. O fenômeno da violência contra crianças e adolescentes, no dizer de Esber (2009) está conectado a atitudes práticas sócio-historicamente constituídas em relação a crianças, adolescentes e mulheres.

No caso de prostituição, e, sobretudo, no contexto da exploração sexual, a ação sexual é violenta ao ser mediada pelo dinheiro, não havendo sexualidade, porque o desejo e o prazer da mulher estão anulados. Ademais, a ausência de autonomia e o estágio incompleto de desenvolvimento infantil ampliam, sobremaneira, os efeitos nefastos do ambiente de 
exploração, que não raramente se estabelece a partir de uma subserviência econômica, emocional ou social da criança.

Alguns estudos recentes defendem que é falacioso o discurso de que os jovens são sempre, e inevitavelmente, objetos passivos e entendem que considerar a prostituição do(a) jovem como exploração não se adequa à realidade contemporânea. Defende-se aí a ideia de que os jovens podem estar exercendo a sua própria vontade. Ao perceber os jovens como atores sociais, deve ser-lhes garantido o direito da autonomia ou exercício de sua própria vontade, que lhe permitam seu envolvimento em transações sexuais comerciais, não caracterizando aí qualquer forma de exploração. Defendem, assim, que o jovem não pode ser confundido com criança e deve ser considerado como adulto, retirando-o da categoria de vítima e explorado.

Compreende-se que essa defesa da autonomia do jovem é equivocada, pois não se nega aqui o direito a sexualidade do jovem, no entanto, há que se distinguir que a sexualidade da criança, do jovem e do adulto não são da mesma ordem, prescindido a da criança e a do jovem de uma liberdade e autonomia real. Ferrari e Vecina (2002) compreendem a submissão da criança pela forma impositiva e autoritária como prática de se relacionar com as crianças, tirando-lhes o direito de expressar pensamentos, opiniões e sentimentos. A ausência de liberdade no caso da exploração sexual decorre da falta de autonomia, pois,

... a liberdade não é a escolha voluntária ante várias opções mas a capacidade de autodeterminação para pensar, querer, sentir e agir. É autonomia. Não se opõe à necessidade (natural ou social), mas trabalha com ela, opondo-se ao constrangimento e à autoridade. Nessa perspectiva, ser sujeito é construir-se e constituir-se como capaz de autonomia numa relação tal que as coisas e os demais não se ofereçam como determinantes do que somos e fazemos, mas como o campo no qual o que somos e fazemos pode ter a capacidade aumentada ou diminuída, segundo nos submetamos ou não à força e à violência ou sejamos agentes dela (Chauí,1985 p.36)

O trabalho e a liberdade sexual são, antes de tudo, direitos do cidadão os quais devem ser exercidos livremente, sem, contudo, privar o indivíduo dos demais direitos essenciais, como a saúde, a educação, a opinião e a dignidade. No caso de exploração sexual, são violados massivamente vários direitos: à dignidade, à vida, à segurança, à integridade física, à saúde reprodutiva, à não discriminação, à educação, à liberdade de movimento e a não sofrer tortura, maus-tratos ou penas cruéis, inumanas ou degradantes. Constata-se que a exploração sexual comercial trata crianças e adolescentes como coisas, como mercadorias, que são barganhadas em prol de interesses vis. Viola, sobretudo, a sua condição de protagonista, a partir de direitos 
fundamentais que consiste no direito à vida e à saúde física e mental, conforme disposto no art. $7^{\circ}$, do ECA.

Dessa forma, a exploração sexual de crianças e adolescentes é considerada uma afronta aos direitos humanos, porque fere o princípio angular da dignidade humana que representa a possibilidade de autodeterminação do ser humano e sua capacidade de ter uma vida plena, com direito à integridade física e psíquica, e que permite a sua autorrealização, no aspecto individual e social, de forma a cotejar a complexidade da natureza humana na representação jurídica do ser humano num marco de uma sociedade de direito. A dignidade do outro estará sempre vinculada ao reconhecimento recíproco de que o ser humano não pode ser degradado ou coisificado, o que constitui a base da conivência humana em sociedade. (SOARES, 2010).

\section{3 “CAMILA, CAMILA": REPRESENTAÇÃO MUSICAL DA EXPLORAÇÃO SEXUAL DE UMA ADOLESCENTE}

Ante as relações de poder que punham a figura feminina em uma situação de vulnerabilidade e inferioridade, é que eclodiram os primeiros movimentos em defesa da mulher, mais precisamente nos anos 80, do século $\mathrm{XX}$, quando surgiram as noções teóricas iniciais sobre desigualdade de gênero. Os constantes estudos desenvolvidos nas academias e pela Militância Feminista da época, como afirma Grossi (1994) enfatizavam que não eram as diferenças biológicas entre mulheres e homens que fomentavam a violência de gênero contra a mulher, mas os papéis que cada um deles ocupava em uma sociedade de cultura essencialmente patriarcal.

A obra musical "Camila, Camila" interpretada pela banda "Nenhum de Nós", uma das músicas mais executadas no final da década dos anos 1980, buscou evidenciar umas das formas mais graves de violação dos direitos de criança e de adolescentes. A questão da violência de gênero traduzida na obra musical, denota toda a fragilidade de uma menina/moça acuada e impotente face a uma relação indesejada. Ante a essas relações de poder que punham a figura feminina em uma situação de vulnerabilidade e inferioridade, é que eclodiram os primeiros movimentos em defesa da mulher, nessa mesma época, ou seja, nos anos 80, do século XX, quando surgiram as noções teóricas iniciais sobre desigualdade de gênero. Os constantes estudos desenvolvidos nas academias e pela Militância Feminista da época, como afirma Grossi (1994) enfatizavam que não eram as diferenças biológicas entre mulheres e homens que 
fomentavam a violência de gênero contra a mulher, mas os papéis que cada um deles ocupava em uma sociedade de cultura essencialmente patriarcal.

A música "Camila, Camila", tem a seguinte letra:

Depois da última noite de festa

Chorando e esperando amanhecer, amanhecer...

As coisas aconteciam com alguma explicação

Com alguma explicação...

Depois da última noite de chuva

Chorando e esperando, amanhecer, amanhecer..

Às vezes peço a ele, que vá embora, que vá embora

Oh!...Camila! Ah!, Camila, Camila...

Eu que tenho medo até de suas mãos

Mas o ódio cega e você não percebe

Mas o ódio cega...

E eu que tenho medo até do seu olhar

Mas o ódio cega e você não percebe

Mas o ódio cega...

A lembrança do silêncio

Daquelas tardes, aquelas tardes...

Da vergonha do espelho

Naquelas marcas, daquelas marcas...

Havia algo de insano aqueles olhos

Olhos insanos, oh!

Os olhos que passavam o dia

A me vigiar, ah!, a me vigiar, ah!

Oooooh!...

Camila! Ah! Camila! Camila!

Camila! Ah! Oh! Camila! Camila!...(2x)

E eu que tinha apenas 17 anos

Baixava a minha cabeça pra tudo

Era assim que as coisas aconteciam

Era assim que eu via tudo acontecer...

E eu que tinha apenas 17 anos

Baixava minha cabeça pra tudo

Era assim que as coisas aconteciam

E era assim que eu via tudo acontecer...

Camila! Ah! Oh Camila!

Camila! Ah! Oh! Camila! Ah! Camila!...

Ooooooooh! (CORRÊA; STEIN, 1987).

Um dos autores da letra e intérprete musical, Thedy Corrêa, em entrevista concedida ao site Childhoold afirmou que sentiu a necessidade de falar sobre o assunto e que lamenta que 
muitas músicas brasileiras ainda estimulem o sexismo e deturpem a imagem da mulher, quando deveriam conscientizar contra a violência sexual. Sobre a composição da música afirmou que:

Essa canção foi inspirada em fatos reais, envolvendo uma jovem que nós conhecíamos na época, em 1985. Era uma colega de escola bastante bonita com um namorado violento. Ficávamos intrigados com os motivos que levavam uma garota assim a se submeter e ser maltratada por um rapaz tão estúpido. Ouvimos algumas histórias de situações constrangedoras que ela sofreu e essa foi nossa "faísca criadora" para uma canção que falasse da violência contra a mulher. Por isso os "olhos insanos", a "vergonha do espelho naquelas marcas", além da tristeza e indignação na melodia. Hoje, ela vive super bem, tem uma linda família e está bem longe desse antigo namorado... Ainda bem!

[...]

A violência sexual era pior nos anos 80 , porque não era tão debatida quanto hoje. Existe maior consciência por parte da sociedade e mecanismos de proteção que são fruto desta discussão. (DESDE..., 2012).

Os versos da canção denotam pavor, medo, vergonha e submissão. Apresentam um contexto de violência e degradação moral impostas pelo autoritarismo sexista culturalmente aceito pela sociedade. O pacto do silêncio nada mais é do que a representação da cultura machista que condiciona a mulher a uma postura passiva frente à violência sexual. As marcas veladas do silêncio que envergonham e que empobrecem o se sentir mulher. $\mathrm{O}$ silêncio da vítima é ocasionado também pela naturalização da violência contra a mulher, e nas palavras de Veronese (2012) é oriunda de uma universalização de "uma grotesca cultura que nos esvazia, que aniquila nossos mais preciosos valores, que nos desautoriza enquanto seres humanos não somente por banalizar a violência, mas por suscitar a sua reprodução". A falta de autonomia e da liberdade claramente representada pelo grito da adolescente "Camila", ou clamar por um socorro que nunca chegou.

Muitas estrofes da música denotam explicitamente que Camila sofreu violência sexual, primeira e segunda estrofes, dando a entender que ela foi violentada após retornar de uma festa, ficando até o dia amanhecer buscando explicação. A sequência das estrofes dá a ideia de nítida repetição dos fatos, ou seja, de contínua e frequente práticas de exploração sexual, sem qualquer vontade e interesse da narradora. A falta de autonomia transparece nos sentimentos de medo e ódio narrados no discurso. O ódio transparece recíproco entre vítima e agressor, não permitindo enxergar os verdadeiros sentimentos que nutrem um pelo outro. Percebe-se na letra da música uma mescla de emoções e sentimentos comuns nas vítimas de abuso sexual, apresentados nos estudos de Esber (2009) quais sejam, vergonha, culpa, arrependimento, ódio e muitas vezes até sentimento de vingança. Muitos autores comungam com a opinião de que a violência sexual 
contra crianças e adolescentes é uma violência contra o corpo e contra a alma (MADANES, 1997).

Além do sofrimento selado pelo silêncio, muito comum em casos de violência sexual, pois como afirma Furnis (1993) o medo pode acarretar a manutenção do segredo sobre a violência, as cicatrizes também eram encobertas pela vergonha de se mostrar vítima de crime dessa natureza. Se esse é o comportamento das vítimas nos dias de hoje, quiçá nos anos 1980.

A canção deixa transparecer uma conivência social ao se calar diante do pedido de socorro da adolescente, que se revelava infeliz por um longo período de frequentes casos de exploração. A melodia, que se mostra sofrida e em tom de compaixão, denota solidariedade a Camila por tamanho sofrimento. Ao mesmo tempo, soa como pedido de socorro a tantas outras "Camilas" presentes na sociedade.

Ressalta-se que a adolescente retratada na música é explorada por ausência completa de autonomia na prática sexual, evidenciada pelo sofrimento enfatizado no seu clamor de socorro. Denota-se ainda, sua vitimização ${ }^{1}$ em razão do abandono social, pela ausência de percepção da sociedade do seu sofrimento, e que acaba fortalecendo a ideia da naturalização da prática dessa violência, e da insignificância da punição do agressor.

Porém, destaca-se que, como afirma Leal e Leal (2002) a ousadia em denunciar este fenômeno ao Brasil e ao mundo não é apenas para demonstrar a crise da modernidade, da ética e da democracia, mas indicar que existe uma sociedade indignada com as respostas dos sistemas de produção e de valores.

O sofrimento e o grito de Camila representa várias Camilas não tão distantes no tempo e no espaço.

\section{A EXPLORAÇÃO SEXUAL NO CONTEXTO SOCIAL}

A exploração sexual de crianças e adolescentes é um tema que diz respeito não somente aos sujeitos objeto da exploração, mas também a toda a sociedade. A exploração sexual é uma das formas de violência do mundo atual

O abuso sexual infantil é uma forma de violência que envolve poder, coação e/ou sedução. É uma violência que envolve duas desigualdades básicas: de gênero e geração. $\mathrm{O}$ abuso sexual infantil é frequentemente praticado sem o uso da força física e não deixa marcas visíveis, o que dificulta a sua

\footnotetext{
1 A palavra vitimização ao invés de vítima aqui é utilizada pela compreensão dada por Faleiros (2000) que reconhece no sujeito a capacidade de compreensão e reação de uma ou outra forma.
} 
comprovação, principalmente quando se trata de crianças pequenas. $\mathrm{O}$ abuso sexual pode variar de atos que envolvem contato sexual com ou sem penetração a atos em que não há contato sexual, como o voyeurismo e o exibicionismo. (ARAUJO, 2002, p. 5)

Conforme salienta Leal (1999, p. 9), a situação de pobreza e a violência doméstica intrafamiliar e extrafamiliar têm sido condições fundamentais para que milhares de crianças e adolescentes se transformem em grupos vulneráveis de exploração sexual comercial e outros tipos de violência. Em razão da pobreza, muitas crianças e adolescentes são induzidos à prática da prostituição, a qual, neste caso, é considerada como exploração sexual, em razão da falta de autonomia das vítimas.

No caso de exploração sexual de crianças e adolescentes, o que está em jogo é a satisfação do desejo sexual (de propriedade do consumidor), o lucro (apropriado pelo mercado) e as relações de poder desiguais instrumentalizadas sob a égide da exploração e dominação de classe, de gênero, raça/etnia e geração (crianças e adolescentes). (LEAL: LEAL, 2002, p. 31).

Ressalta-se que, nesse caso, o que ocorre é a exploração sexual, distinta da prostituição, a qual, na maioria das vezes, é um ato voluntário, em que se configura a liberdade de escolha entre praticá-lo ou não, o que não ocorre na exploração. A sexualidade feminina historicamente foi resignada ao interesse do homem. A marginalização sexual da mulher está arraigada nos ditames históricos e culturais, vez que as mulheres são educadas por mulheres, numa sociedade onde a virilidade e o prestígio do macho estão longe de serem apagados (GOIS, 1991, p. 119). Meninas são orientadas a atuar como filhas e mães, mas não como mulheres. E, sobre essa construção simbólica, complementa Beauvoir “[...] o opressor não seria tão forte se não tivesse cúmplices entre os próprios oprimidos.”. (2005, p. 82).

A exploração sexual de crianças e jovens menores de 18 anos envolve situações de exploração, na qual os jovens se relacionam com pessoas (uma pessoa ou mais pessoas) e recebem "algo" (por exemplo, alimentos, alojamento, drogas, álcool, cigarros, afeto, presentes, dinheiro, etc.) em troca de atividades sexuais. Em todos os casos, os que exploram a criança/jovem têm poder sobre eles, em virtude da sua idade, sexo, intelecto, força física e/ou recursos econômicos, ou outros.

Embora os termos "abuso" e "abuso sexual" não foram definidos de forma exaustiva em qualquer instrumento internacional, muitas leis nacionais fornecem uma definição. $\mathrm{O}$ abuso sexual de crianças pode ser interpretado como alguma forma de violência sexual cometida contra a criança, por exemplo, estupro. $\mathrm{O}$ abuso sexual pode ser definido como ato ou jogo sexual em que o adulto submete a criança ou o adolescente (relação de poder desigual) para se 
estimular ou se satisfazer sexualmente, impondo-se pela força física, pela ameaça ou pela sedução, com palavras ou com a oferta de presentes (INFÂNCIA.., 2002). Ela difere da “exploração sexual”, na medida em que pode cobrir situações na qual não há nenhuma remuneração em dinheiro ou em espécie; por exemplo, estupro, incesto e relação sexual em situações não-comerciais. Essas situações apresentam-se no contexto familiar, nas escolas e em outros ambientes. $\mathrm{O}$ abuso sexual é também um componente inerente de exploração sexual em situações comerciais, como, por exemplo, em relação aos bordéis que exploram crianças no comércio do sexo, e do uso da Internet para ajudar a gerar e/ou transmitir pornografia infantil.

A exploração sexual de crianças e adolescentes consiste em uma das formas de violência mais grave do mundo atual, que atinge a integridade física, moral e psicológica da criança ou do adolescente.

\section{A EXPLORAÇÃO SEXUAL E A VIOLÊNCIA DE GÊNERO}

A mulher sempre foi vista pela sociedade como um papel secundário, relegada aos afazeres domésticos e sevícias do marido. Sua contribuição como membro da sociedade era o de procriadora, de esposa dedicada, um mero complemento do marido. Essa condição era entendida como da natureza da mulher, por ser vista como fisicamente fracas, moralmente frágeis, e intelectualmente inferiores ao homem, evidenciavam a supremacia do marido em relação às mesmas.

Segundo Moreira et al (2011) a violência é um fenômeno que se manifesta desde os primórdios da humanidade, podendo ser compreendida como um produto de relações desiguais, geralmente materializadas contra nações, segmentos populacionais ou pessoas que se encontram em alguma desvantagem física, econômica, cultural ou emocional.

A exploração sexual perpassa por uma construção social edificada pelas culturas patriarcais, que considera as mulheres como seres para e de outros. Elas se encontram limitadas em torno da sua sexualidade, do seu corpo e do seu sexo para satisfação do prazer do outro. A sexualidade torna-se, assim, uma moeda de troca, que, no caso de crianças e adolescentes, não se identifica a autonomia da vontade.

Ao discorrer sobre violência e submissão no contexto da violência contra a mulher, Santos (2009, p. 08) ressalta:

A violência perpassa, de forma inexorável, as mais diversas sociedades, infligindo sofrimentos que vão da dor física ao medo, da perda de identidade à morte a muitas pessoas. É um dos principais problemas da atualidade, mas 
ao longo da história da humanidade, esteve presente nas relações entre indivíduos e povos. Os exemplos de crueldade cometidos por seres humanos contra outros seres humanos são inúmeros. Vão da violência diária, tida como corriqueira, àquelas históricas como o assassinato de cristãos nas arenas romanas, o holocausto dos judeus nos campos de concentração, a inquisição, o extermínio das bruxas em fogueiras e a escravidão. Essas passagens históricas são emblemáticas por indicarem uma intrínseca relação entre os atos violentos e a demonstração de poder, de controle e seu efeito mais visível: a submissão do outro.

A exploração sexual de crianças e adolescentes é definida como uma relação de poder e de sexualidade mercantilizada, que visa à obtenção de proveitos por adultos, que causa danos biopsicossociais aos explorados, que são pessoas em processo de desenvolvimento. (FALEIROS, 2000, p. 72). Denota-se, assim uma das formas de violência de gênero:

A violência de gênero se apresenta como uma forma mais extensa e se generalizou como uma expressão utilizada para fazer referência aos diversos atos praticados contra mulheres como forma de submetê-las a sofrimento físico, sexual e psicológico, aí incluídas as diversas formas de ameaças, não só no âmbito intrafamiliar, mas também abrangendo a sua participação social em geral, com ênfase para as suas relações de trabalho, caracterizando-se principalmente pela imposição ou pretensão de imposição de uma subordinação e controle de gênero masculino sobre o feminino. A violência de gênero se apresenta, assim, como um 'gênero', do qual as demais, são espécies. (SOUZA, 2007, p. 35)

Campagnoli (2003) conceitua gênero explicitando as diferenças construídas entre homens e mulheres, justificando que as desigualdades entre esses atores são naturais, pois suas peculiaridades encontram fundamentos em aspectos biológicos, fugindo, portanto, de qualquer aspecto social.

Simone de Beauvoir (1970, p. 179) afirma que: “[...] a história mostrou-nos que os homens sempre detiveram todos os poderes concretos, desde os primórdios tempos do patriarcado, julgaram útil manter a mulher em estado de dependência, seus códigos estabeleceram-se contra elas.” E continua a explanar sobre a construção simbólica da superioridade masculina, pautada, inicialmente, sob conceituações biológicas:

A mulher é mais fraca do que o homem; ela possui menos força muscular, menos glóbulos vermelhos, menor capacidade respiratória; corre menos depressa, ergue pesos menos pesados, não há quase nenhum esporte em que possa competir com ele; não pode enfrentar o macho na luta. (BEAUVOIR, 1970, 174) 
A condição de pobreza, em muitos casos, retira do cidadão os valores morais e éticos, que ficam subestimados devido à necessidade de sobrevivência. Em razão da pobreza, a exploração do trabalho dos filhos é vista como paliativa ou até como "salvação" da realidade vigente. É através do trabalho de meninos e meninas, sacrificados e coisificados para minorar o sofrimento dos demais membros da família, que se busca uma solução para auferir renda.

A criança e o adolescente, na ótica menorista em vigor até o advento da Constituição Federal de 1988, eram meros objetos de toda uma ideologia tutelar, de uma cultura que coisificava a infância. Já sob a ótica de um novo direito - o Direito da Criança e do Adolescente -, a criança e o adolescente são compreendidos como sujeitos cujas autonomias estejam sendo desenvolvidas, o que implica elevá-los a autores da própria história, portanto atores sociais, seres que marcam com suas vidas o atual processo histórico. (VERONESE, 2012).

Considerando que a proibição da exploração sexual atinge crianças e adolescentes, e conforme estudos já realizados, esse tipo de exploração estende-se, de forma maciça, a um maior número de mulheres. Reconhece-se, assim, que a condição da mulher na sociedade e na família é também uma vertente da exploração sexual, em especial a mulher pobre, que, historicamente, era considerada uma mulher desviada dos princípios éticos e morais. A complexidade do problema envolve questões como o sistema patriarcal, a questão de gênero, a questão racial, a apartação social e o interesse pela emancipação econômica/cultural/sexual. Nesse sentido,

\begin{abstract}
No caso da violência contra a mulher, tal hipossuficiência decorre de todo este desenvolvimento histórico, antes resumido, que a colocou em uma posição submissa frente ao homem, encarada como o 'sexo frágil', detentora de menos responsabilidades e importância social. O homem, desde a infância, foi sendo preparado para atitudes hostis, para arrostar perigos e desafios, mesmo com o uso da violência. As próprias atividades lúdicas normalmente incitadas à infância masculina são relacionadas ao uso da força, das armas, do engenho, ao passo que a mulher, pelo contrário, foi historicamente preparada para a subserviência e a passividade. (PORTO, 2007, p. 18)
\end{abstract}

Uma ampla compreensão do percurso histórico-social e sócio-político da violência contra a mulher encontra escopo quando se percebe que o fenômeno decorre de um processo histórico profundamente relacionado ao gênero. As construções simbólicas que impõem a homens e mulheres determinados papéis, identificando-os dentro de sua cultura, acabam por limitar as potencialidades dos gêneros, criando rotulações sobre o que seria ou não permitido a cada um deles no âmbito social.

As diferenças que acarretam a violência de gênero têm sua concepção no arcabouço da história da humanidade, em que os homens detinham o poder sobre vida e morte dos membros 
de sua família, e a autoridade das mulheres era comparada à das crianças (BOURDIEU, 2002, p. 160). As relações de gênero são, primordialmente, relações de poder, e na esfera da sexualidade feminina evidencia-se o controle e o poder masculino.

Por essa razão, diz-se que a cultura de violência contra a mulher é inerente ao comportamento humano, vez que se trata de expressão cultural que ultrapassa gerações, renovando-se de forma diversificada com o passar dos anos. A barreira histórica dos séculos não impediu a sua propagação. Chauí (1985) conceitua violência não como violação ou transgressão de normas, regras e leis, mas sob dois outros ângulos:

Em primeiro lugar, como conversão de uma diferença e de uma assimetria numa relação hierárquica de desigualdade, com fins de dominação, de exploração e opressão. Em segundo lugar, como a ação que trata um ser humano não como sujeito, mas como coisa. Esta se caracteriza pela inércia, pela passividade e pelo silêncio de modo que, quando a atividade e a fala de outrem são impedidas ou anuladas, há violência (CHAUÍ, 1985, p. 35)

Desde a infância, esses agentes são orientados para valores culturais opostos, enquanto os meninos são educados para o uso da força física, valorização da agressividade, ações de dominação e realização, ainda precoce, de sua vida sexual, as meninas são conduzidas pelo caminho da submissão, passividade e sentimentalismo, a sua valorização está diretamente ligada à feminilidade, dependência e capacidade de sedução.

Por ser acontecimento corriqueiro e já banalizado por grande parte da sociedade, a frequência das práticas de violência de gênero ganhou significativa proporção, isto porque aqueles que não a praticam entendem-na como acontecimento trivial e admissível.

Para Lima e Santos (2009), a violência contra a mulher é uma das mais brutais formas de transgressão aos Direitos Humanos, pois não se trata apenas de maus-tratos físicos, mas sexual, psicológico, moral e também econômico. É a legitimação de frontal desrespeito às garantias constitucionais à saúde, à liberdade e à dignidade.

Impende destacar, contudo, a dificuldade de ajustar uma conduta específica como ato de violência de gênero, isto porque, na grande maioria das vezes, o fato de estar habituada com um ambiente de limitações comportamentais, envolvida pelo complexo histórico de inferioridade e subjugação, a vítima não reconhece tais atos como violência.

Nesse diapasão, a exploração sexual de crianças e adolescentes é considerada como abominável e rechaçada pela legislação vigente, em defesa da proteção integral contemplada no art. 227 da Constituição Federal, em comunhão com todas as normas internacionais de proteção à infância. 


\section{CONCLUSÃO}

A análise sobre a exploração sexual de crianças e adolescentes que tomou como parâmetro a canção "Camila" interpretada pela banda "Nenhum de Nós" demonstrou que essa é uma das expressões da questão social, a partir dos desdobramentos históricos condicionados das transformações socais e seus reflexos.

Constatou-se na canção a condição de vítima e de explorada da adolescente. A ausência plena de liberdade sobre o seu próprio corpo, e satisfação e prazer sexual. A condição de explorada e a necessidade de auxílio para sair dessa situação restou evidenciada.

A construção cultural da condição subordinada/oprimida da mulher é uma forma de expressão da violência naturalmente incorporada na sociedade. A busca incessantemente almejada pela igualdade de gêneros ainda não foi alcançada, ainda que essa esteja formalmente presente no discurso legislativo, em especial na Constituição Federal, mostrando-se essa com eficácia ideológica frente as barreiras culturais muito distantes de um modelo legal igualitário.

O fenômeno da exploração sexual contra crianças e adolescentes mostra-se como uma das formas de violência de gênero, em suas origens retroagem às concepções socioculturais em que a mulher é concebida como cidadã de segunda categoria, e dessa maneira, vista como propriedade do homem ou a ele submetido, situação se que justifica a sistemática discriminação e a violência que historicamente fora direcionada a este gênero.

Para combater a violência sexual contra a mulher é necessário não só um aparato legislativo garantidor de direitos, é necessário ainda uma compreensão sobre o ser feminino e o ser masculino que incorpore uma visão humanista, que possibilite uma eficácia das normas que visam a igualdade. Mister se faz que o enfrentamento da violência sexual contra crianças e adolescentes possibilite garantir que os direitos violados e no contexto pós-revelação sejam resgatados. As medidas de proteção às vítimas são imprescindíveis para cumprir a efetivação das normas constitucionais e internacionais relativas à infância.

Impõe-se ainda destacar a necessidade de desmistificar os conhecimentos produzidos, compreender o fenômeno, e reconhecer que o foi deflagrado um processo de proteção à infância mas que esse não se esgotou, e que merece e deve ter continuidade. 


\section{REFERENCIAS}

ARAUJO, Maria de Fátima. Violência e abuso sexual na família. Psicologia em Estudo, Maringá, v. 7, n. 2, p. 3-11, jul./dez. 2002.

BEAUVOIR, Simone de. O segundo sexo - Fatos e mitos. São Paulo: Difusão Europeia do Livro, 1970.

BOURDIEU, Pierre. A dominação masculina. Trad. Maria Helena Kühner. 11. ed. Rio de Janeiro: Bertrand Brasil, 2002. 160 p.

CAMPAGNOLI, F. P. F., Adriana. A mulher, seu espaço e sua missão na sociedade. Análise crítica das diferenças entre os sexos. Revista Emancipação: Departamento de Serviço Social, Ano 3, editora Uepe; v. 03, n. 1, 2003.

CHAUÍ, Marilena. Participando do debate sobre a mulher e violência. In: ; CARDOSO, Ruth; PAOLI, Maria Célia (Orgs.). Perspectivas antropológicas da mulher: sobre mulher e violência. Rio de Janeiro: Zahar, v.4, 1985.

CORRÊA, Thedy. STEIN, Carlos. Camila, Camila. Execução Banda "Nenhum de Nós". Álbum "Nenhum de Nós". (1987). BMG, 1987.

DESDE os anos 80, música "Camila, Camila"” alerta sobre a violência sexual. In: Childhood. Entrevista de Thedy Correa. (17 de maio de 2012). Disponível em:

$<$ http://www.childhood.org.br/desde-os-anos-80-musicacamila-camila-alerta-sobre-aviolencia-sexual>. Acesso em: 28 mar. 2016.

ESBER, Karen Michel. Autores de violência sexual contra crianças e adolescentes. Goiânia: Cânone Editorial, 2009.

FALEIROS, Eva T. Silveira. Repensando os conceitos de violência, abuso e exploração sexual de crianças e adolescentes. Brasília: Thesaurus, 2000.

FERRARI, D. C.A.; VECINA, T.C.C. O fïm do silêncio na violência familiar: teoria e prática. São Paulo: Ágora, 2002.

FURNISS, Tilman. Abuso sexual da criança: uma abordagem multidisciplinar. Porto Alegre: Artes Médicas, 1993.

GÓIS, M.M.S. Aspectos históricos e sociais da anticoncepção. Reproduo, v. 6, n. 3, p. 11924, 1991.

GROSSI, Miriam Pillar et al. Novas/velhas violências contra a mulher no Brasil. Revista Estudos Feministas, Santa Catarina, v. Especial, n. 2, p. 473-474. Julho/1994. Semestral. Disponível em: 〈http://miriamgrossi.paginas.ufsc.br/files/2012/03/16179-49803-1-PB.pdf〉. Acesso em: 20 nov. 2015.

INFÂNCIA na mídia - Pesquisa ANDI/IAS (Issn 1519-1702) Ano 7 / Número 12 / Março 2002. Disponível em: < file:///C:/Users/Usu\%C3\%A1rio/Downloads/infmidia12_0.pdf>. Acesso em: 27 dez. 2015. 
LEAL, Maria Lúcia Pinto. A exploração sexual comercial de meninos, meninas e adolescentes na América Latina e Caribe (Relatório Final-Brasil). 2. ed. Brasília: CECRIA: INN, Ministério da Justiça, UNICEF, CESE, 1999.

LEAL, Maria Lucia; LEAL, Maria de Fátima (orgs). Pesquisa sobre tráfico de mulheres, crianças e adolescentes para fins de exploração sexual comercial - PESTRAF: Relatório Nacional - Brasil. Brasília: CECRIA, 2002.

LEAL, Maria Lúcia; LEAL, Maria de Fátima. Tráfico de Mulheres, crianças e adolescentes para fins de exploração sexual e comercial no Brasil- Realidades e Desafios. In LIBÓRIO, Renata Maria Coimbra; SOUSA M. Gomes (Orgs). A exploração sexual de crianças e adolescentes no Brasil: reflexões teóricas, relatos de pesquisas e intervenções psicossociais. São Paulo: Casa do Psicólogo, 2004; Goiânia, GO: Universidade Católica de Goiás, 2004.

MADANES, C. Sexo, amor e violência. Estratégias para a transformação. Campinas: Editorial Psy, 1997.

MOREIRA, Virginia; BORIS, Georges Daniel Janja Bloc and VENANCIO, Nadja. O estigma da violência sofrida por mulheres na relação com seus parceiros íntimos. Psicol. Soc.2011, vol.23, n.2. Disponível em: www.scielo.br/scielo. Acesso em: 19 março de 2016.

PORTO, Pedro Rui da Fontoura. Violência doméstica e familiar contra a mulher: Lei 11.340/06: análise crítica e sistêmica. Porto Alegre: Livraria do Advogado Editora, 2007.

SANTOS, Edilma Rodrigues dos. DISCURSOS MIDIÁTICOS SOBRE VIOLÊNCIA CONTRA A MULHER: Estudo dos jornais Diário de S.Paulo e Folha de S.Paulo. 2009. II Colóquio Binacional Brasil-México de ciências da comunicação. São Paulo. 01 A 03 de Abril de 2009. Disponível em: https://www.espm.br. Acesso em 28 out.2015.

SOARES, Ricardo Mauricio Freire. O princípio constitucional da dignidade pessoa humana. São Paulo: Saraiva, 2010.

SOIHET, Rachel. Mulheres pobres e violência no Brasil urbano. In: DEL PRIORI, Mary. (org.). História das mulheres no Brasil. 10. ed. São Paulo: Contexto, 2012.

SOUZA, Sérgio Ricardo. Comentários à lei de combate à violência contra a mulher. Curitiba: Juruá, 2007.

VERONESE, Josiane Rose Petry. Violência e exploração sexual infanto-juvenil: uma análise conceitual. Psicol. clin. vol.24 no.1 Rio de Janeiro 2012. Disponível em: http://dx.doi.org/10.1590/S0103-56652012000100009 . Acesso em 20 de outubro de 2015. 